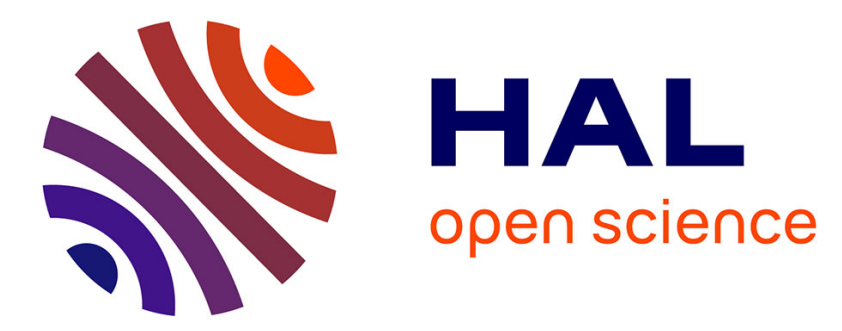

\title{
Heat-pump dehumidifier as an efficient device to prevent condensation in horticultural greenhouses
}

Etienne E. Chantoiseau, Christophe C Migeon, Gérard Chasseriaux, Pierre-Emmanuel Bournet

\section{- To cite this version:}

Etienne E. Chantoiseau, Christophe C Migeon, Gérard Chasseriaux, Pierre-Emmanuel Bournet. Heatpump dehumidifier as an efficient device to prevent condensation in horticultural greenhouses. Biosystems Engineering, 2016, 142, pp.27-41. 10.1016/j.biosystemseng.2015.11.011 . hal-01257561

\section{HAL Id: hal-01257561}

\section{https://institut-agro-rennes-angers.hal.science/hal-01257561}

Submitted on 17 Jan 2016

HAL is a multi-disciplinary open access archive for the deposit and dissemination of scientific research documents, whether they are published or not. The documents may come from teaching and research institutions in France or abroad, or from public or private research centers.
L'archive ouverte pluridisciplinaire HAL, est destinée au dépôt et à la diffusion de documents scientifiques de niveau recherche, publiés ou non, émanant des établissements d'enseignement et de recherche français ou étrangers, des laboratoires publics ou privés.

\section{()ㅜㅇㅜ}

Distributed under a Creative Commons Attribution - NoDerivatives| 4.0 International 


\section{Heat-pump dehumidifier as an efficient device to prevent 2 condensation in horticultural greenhouses

4 Etienne Chantoiseau*; Christophe Migeon; Gérard Chasseriaux; Pierre Emmanuel Bournet

Agrocampus Ouest, UP EPHor Environmental Physics and Horticulture Research Unit, F-49045 Angers, France.

7

* Corresponding Author (etienne.chantoiseau@agrocampus-ouest.fr)

Corresponding author contact information :

Etienne Chantoiseau
E-mail: etienne.chantoiseau@,agrocampus-ouest.fr
Research Unit EPHor
Agrocampus Ouest, centre d'Angers,
2, rue Le Nôtre
49045 Angers Cedex 01
France

Highlight:

- A heat pump dehumidifier was designed to avoid condensation on ornamental crops

- A $4 \mathrm{~W} \mathrm{~m}^{-2}$ power consumption at the compressor sufficed to prevent condensation

- Heat pump significantly contributed to greenhouse heating, reducing energy costs

- Total operational cost was lower than estimated for ventilation with an exchanger

- Device profitability is discussed for different countries according to energy cost 


\section{Abstract}

Abstract: In the context of increasing energy costs, alternative methods to the energy consuming venting-heating method must be considered for greenhouse dehumidification. In this paper the performance of a heat pump used as a dehumidifier is investigated. Contrary to the classical control aiming at maintaining the greenhouse air at a relative humidity set point, the considered device is designed as a preventive tool to avoid condensation on the crop and limit the energy consumption. The experimental set up was run during winter inside a $2350 \mathrm{~m} 2$ plastic greenhouse in the West of France for a set temperature of $16^{\circ} \mathrm{C}$. During the experiment, no condensation occurred on the plants with a mean condensation rate of $12 \mathrm{~W} \mathrm{m-2}$ and a mean electrical power of $7.62 \mathrm{~kW}$, for an overall efficiency of 4.9. Moreover, the energy retrieved by vapor condensation was given back to the greenhouse as sensible heat, contributing to the total heating of the greenhouse. While dehumidifying the greenhouse air, the device reduces, or may even rule out the gas consumption. The total energy consumption of the heat pump during the season was compared to simulated values for venting-heating dehumidification, with or without an exchanger. The heat pump dehumidifier was shown to be 6 to 8.5 times less energy consuming than the former and 3-8 than the latter, depending on the exterior climate. Using the energy cost of several significant countries, a preliminary operative cost study was conducted and showed that the heat pump can be competitive as a dehumidification alternative.

\section{Keywords}

Climate Control; Dehumidification; Energy Saving; Evapotranspiration; Heat exchanger. 


\section{Nomenclature}

Latin

$\mathrm{Cp} \quad$ : Specific heat $\left[\mathrm{J}_{\mathrm{kg}} \mathrm{kg}^{-1} \mathrm{~K}^{-1}\right]$

$\mathrm{e}_{\mathrm{o}} \quad$ : Global efficiency of the dehumidifying apparatus [-]

$\mathrm{e}_{\mathrm{T}} \quad$ : Compressor efficiency of the dehumidifying heat pump [-]

ET : Real evapotranspiration $\left[\mathrm{W} \mathrm{m}^{-2}\right]$

$\mathrm{H} \quad$ : Air enthalpy $\left[\mathrm{kJ} \mathrm{kg}^{-1}\right.$ dry air $]$

$\mathrm{m}_{\text {cond }} \quad$ : Condensed water mass on a time step $[\mathrm{kg}]$

$\mathrm{m}_{\text {elim }} \quad$ : Ventilated water mass on a time step $[\mathrm{kg}]$

$\dot{\mathrm{m}}_{\mathrm{w}} \quad$ : Flow rate in the low temperature heating system $\left[\mathrm{kg} \mathrm{s}^{-1}\right]$

$\mathrm{P}_{\mathrm{atm}} \quad$ : Atmospheric pressure (101325 Pa)

$\mathrm{P}_{\text {evap }} \quad$ : Heat pump power exchange at the evaporator [W]

$\mathrm{P}_{\mathrm{LT}} \quad$ : Power released by the low temperature heating system [W]

$\mathrm{P}_{\text {cond }} \quad$ : Heat pump power exchange at the condenser [W]

$\mathrm{P}_{\text {comp }}$ : Electricity consumed at the heat pump compressor [W]

$\mathrm{P}_{\text {elec }}$ : Total electric consumption of the dehumidifying apparatus [W]

$\mathrm{P}_{\text {sens }} \quad$ : Sensible heat exchange at the evaporator [W]

$\mathrm{P}_{\text {sens }} \quad$ : Heat transfer from the soil to the greenhouse [W]

$\mathrm{Q}_{\text {venting }}$ : Heat loss on a time step due to venting heating $[\mathrm{J}]$

$\mathrm{Q}_{\text {exch }}$ : Heat losses on a time step due to venting -heating with air exchanger $[\mathrm{J}]$

$\mathrm{q}_{\mathrm{cond}} \quad$ : Condensed water mass flow rate $\left[1 . \mathrm{h}^{-1}\right]$

$\mathrm{q}_{\mathrm{v}} \quad$ : Inlet air volumetric flow rate $\left[\mathrm{m}^{3} \cdot \mathrm{h}^{-1}\right]$

$\mathrm{r} \quad$ : Humidity ratio $\left[\mathrm{kg}_{\text {vapour }} \mathrm{kg}^{-1}\right.$ dry air $]$

$\mathrm{S} \quad$ : Greenhouse surface $\left[\mathrm{m}^{2}\right]$

$\mathrm{S}_{\text {tray }} \quad:$ Surface of the balance tray $\left[\mathrm{m}^{2}\right]$

$\mathrm{T}:$ : Temperature $\left[{ }^{\circ} \mathrm{C}\right]$

$\mathrm{t} \quad$ : Time [s]

$\mathrm{v} \quad:$ Air velocity $\left[\mathrm{m} \mathrm{s}^{-1}\right]$

$\mathrm{V}$ : Greenhouse interior volume $\left[\mathrm{m}^{3}\right]$

VPD : Vapour pressure deficit $[\mathrm{Pa}]$

Greek

$\Delta \mathrm{t} \quad$ : Recorded time step [s]

$\Delta \mathrm{H}_{\mathrm{v}} \quad$ : Water enthalpy of vaporization $\left[\mathrm{J} \mathrm{kg}^{-1}\right]$

$\varphi \quad:$ : Air relative humidity [\%]

$v \quad:$ Specific volume $\left[\mathrm{m}^{3} \mathrm{~kg}^{-1}\right.$ dry air $]$

$\tau_{\mathrm{r}} \quad:$ Air renewal rate $\left[\mathrm{s}^{-1}\right]$

\section{Subscript}

$1 \quad$ : Air property at the dehumidifying apparatus

2 : Air property at the dehumidifying apparatus

3 : Air property at the dehumidifying apparatus

da : Dry air

dew : Property at dew point

e : : Exterior

i : : Inside the greenhouse

in : Heating system input

out : Heating system output

sat : Saturation condition

$\mathrm{V} \quad$ : Vapour

w : Water

\section{Superscript}

, : Air exchanger output 


\section{Introduction}

\subsection{Dehumidification needs}

Humidity appears as a key factor in climate management of greenhouses. Excessive humidity is sometimes combined with free water appearance (condensation), which creates favourable conditions for the development of fungal diseases (Botrytis cinerea for instance) and enhances leaf necrosis as well as soft and thin leaves. Droplets may also affect light transmission by modifying the optical properties of the cover material, and consequently the photosynthesis activity. During the last two decades, the use of temperature integration with lower temperature set point during the night to save energy led to an increase of relative humidity levels inside greenhouses, and thus enhanced the dehumidification needs to preserve the crop.

A proper dehumidification method must be capable of avoiding water condensation on plant surfaces, which is the first step towards disease prevention as fungi and other pests need water to develop. Condensation must also be limited on the greenhouse cover in order to avoid dripping on the crop. Moreover, the operational cost of a dehumidification method should be as low as possible to remain economically advantageous for the grower.

\subsection{Dehumidification methods based on venting}

\subsubsection{Venting-heating}

Venting-heating method is presently the most common method used by growers for dehumidification (Campen, Kempkes \& Bot, 2009). This method consists of opening the greenhouse to replace the moist greenhouse air by relatively dry outside air. However, the outside air is often colder and must be heated to reach the set point temperature. Even if this method remains acceptable for ornamental crops during the day when solar radiation and outside air temperature are high, it is necessary to reconsider its economic and environmental acceptability at night, dawn and dusk. At that time, venting-heating inevitably leads to an increase in energy consumption and a decrease of the energetic efficiency of the greenhouse. Indeed, data retrieved by Grisey, Pommier, Chantry, Piasentin, and Chassériaux (2007) in France and HDC in United Kingdom (Adams, Langton \& Plackett, 2009) state that venting-heating can account for $20 \%$ of the overall energy consumption of a greenhouse around the year for a tomato crop and a relative humidity set point of $85 \%$ (respectively $12 \%$ for a humidity set point of $90 \%$ ). For crops with lower transpiration rate as is the case for most of the ornamental species, the ventingheating energy consumption should be lower. Nevertheless, due to the fact ornamental crops have lower heating requirements, the venting-heating still accounts for a significant part of the energy consumption. Despite its inefficiency, this method is still used as the installation requirements are only vents and a heating system that are anyway mandatory for ornamental crops under temperate climates. Nevertheless, due to the increase of fossil fuel cost in Europe and environmental impact of heating ( $\mathrm{CO}_{2}$ emission), the energy consumption has become a growing concern and other methods have been investigated to limit the use of the venting-heating method.

\subsubsection{Venting heating with heat exchanger}

The simpler alternative to venting-heating is to retrieve energy from the outgoing warm ant moist air and to transfer it to the incoming colder dry air using an air-air exchanger. The aim is to reduce the heat losses due to the ventilation and thus reduce the heating requirement. As all the heat cannot be retrieved from the outgoing air, 
some energy is still lost. Moreover, a ventilation system is required in order for the air to pass through the exchanger in both directions.

This system was evaluated by de Halleux and Gauthier (1998), using the properties of exchangers used for livestock housing. For a soilless greenhouse tomato crop in Canada, they obtained a 40\% saving with such a device. Rousse, Martin, Thériault, Léveillée \& Boily (2000) conducted a study using a low-cost exchanger specially built for tomato and cucumber production in Canada. For a relative humidity set point of $75 \%$, the exchanger temperature efficiency was $78 \%$ and $84 \%$ for a ventilation rate of 0.9 and 0.5 air changes per hour. The retrieved heat was significant: $1948 \mathrm{~W}$ for 0.5 air changes per hour and $2856 \mathrm{~W}$ for 0.9 air change per hour (of which $40 \%$ was latent heat due to condensation of the outgoing vapour). In the latter case, the power needed for the ventilation was measured to be $637 \mathrm{~W}$ for a $220 \mathrm{~m}^{2}$ greenhouse (that is $2.9 \mathrm{~W} \mathrm{~m}^{-2}$ ) and the relative humidity was not stable and often above 90\%. The authors estimated that a ventilation rate between 2 and 5 air changes per hour would be required to reach the humidity set point and a corresponding increase by 2 to 5 of the power needed for the ventilation.

Nevertheless, the efficiency of such installation remains very high for a limited investment. In their study, Campen, Bot, and de Zwart (2003) analysed a ventilation-heating method with an exchanger in order to compare it with other dehumidification methods. The installation costs were between 8 and $13 € \mathrm{~m}^{-2}$ for a heating gain between 0.5 and $0.84 € \mathrm{~m}^{-2}$ per year depending on the crop (and thus the transpiration). An air-air exchanger is thus a very efficient solution to limit the supplementary energy consumption involved by venting-heating.

\subsection{Dehumidification heat pump}

An alternative to venting-heating is to use a heat pump dehumidifier that removes water vapour from moist air using an electrically driven refrigeration cycle (Boulard, Baille, Lagier, Mermier \& Vanderschmitt, 1989). The goal is to limit the energy consumption by recycling the inside air instead of heating cold outside air and to provide the energy retrieved from water vapour condensation back to the greenhouse. Consequently, the main advantage of such a device is to minimise energy losses by re-using the energy extracted through condensation.

\subsubsection{Use in horticultural climate control}

To our knowledge, the first experimental works on using a heat pump for dehumidifying were conducted at the end of the 1980's, for example, Boulard et al. (1989) and Chassériaux (1987).

Dehumidification uses mainly air-air heat pumps. The installed devices could consist of several small units dispatched on the greenhouse surface (Campen \& Bot, 2001) but most of the previous studies were based on one larger unit for the entire greenhouse. For the latter, a system to homogenise the climatic conditions must be installed, thus the initial investments in the homogenisation apparatus are expensive and deprive the economic interest of the device by increasing the payback time to more than 30 years (Campen et al., 2003), although a unique pump generally has a larger Coefficient Of Performance (COP) than several small ones. Moreover, the use of a ventilation system implies a higher energy consumption although it guarantees a more homogeneous greenhouse climate.

\subsubsection{Control strategies}

Experimental and simulated attempts with dehumidifying systems focused on maintaining a relative humidity set point on crops with large leaf area index (LAI): Boulard et al. (1989) tried to maintain a relative humidity of 
$75 \%$ in a greenhouse with a tomato crop at $16^{\circ} \mathrm{C}$ and Campen et al. (2003) performed an analysis on simulated data for a relative humidity set point of $85 \%$ for night temperatures between 18 and $20^{\circ} \mathrm{C}$ for rose, tomato, sweet pepper and cucumber.

The former pointed out the ability of such apparatus to suppress the condensation on the cover by using a $2 \mathrm{~kW}$ heat pump for a $400 \mathrm{~m}^{2}$ greenhouse. However, the relative humidity set-point of $75 \%$ at $16^{\circ} \mathrm{C}$ was difficult to maintain and a relative humidity around $90 \%$ was usual. Indeed, the water retrieval involved an increase of the vapour pressure deficit (VPD), and thus an increase of the crop transpiration. For high LAI crop, the transpiration largely compensated the condensation (Bakker, 2009), involving large dehumidification needs. In the study of Campen et al. (2003), the dehumidifying heat pump made it possible to avoid condensation for a maximum electric consumption at the compressor of 20 and $31 \mathrm{~W} \mathrm{~m}^{-2}$ for rose and cucumber respectively. The considered apparatus however was not economically interesting, mostly due to the high cost of the exchanger (aluminium tubes) that accounted for more than two thirds of the installation cost. However, the operational cost of the solution displayed an interesting saving for most of the crops, from $0.5 € \mathrm{~m}^{-2}$ for sweet pepper to $1.15 € \mathrm{~m}^{-}$ ${ }^{2}$ for rose.

As pointed out by Boulard et al. (1989), avoiding dew point on the roof and crop was relatively fast and easy in a tomato greenhouse, but significantly reducing the inside air humidity was very energy consuming, particularly at dawn and dusk. Hence, the investment cost of the dehumidification heat pump could not be balanced by operational gains and the economic interest of such apparatus was null at that time.

The aim of this paper is to analyse the performance and to estimate the operational cost of a dehumidification heat pump used in place of venting-heating to avoid condensation while maintaining a given temperature set point at night. Contrary to previous published studies, the apparatus used in the present study acts as an anticipative tool to avoid condensation rather than maintaining a relative humidity set point during the night. Dehumidification is thus limited to what is strictly needed to avoid condensation at night. The characteristics of the device used in the present work were established from the previous works of Chasseriaux and Gaschet (2009) who used a dynamic model of water vapour exchanges to determine changes in the temperature and moisture concentration at the outlet of the evaporator. After a description of the experimental set up, the dehumidification strategy is presented. Experimental results were obtained for ornamental crops in north western France during the winter and the beginning of spring of 2010-2011. The energy consumption of the dehumidification as well as the heating requirement were assessed and compared to the consumption of ventingheating methods. This made it possible to compare the operating cost of different dehumidification methods. Finally, a dehumidification strategy is proposed to choose the most efficient dehumidification method according to outside climatic conditions and energy costs.

\section{Materials and methods}

\subsection{Greenhouse}

\subsubsection{Generality}

The experiment was conducted inside a $2353 \mathrm{~m}^{2}$ (51.2 m width $\times 45.96 \mathrm{~m}$ length $\times 4 \mathrm{~m}$ height) double wall inflatable greenhouse located in north western France $\left(47.69216^{\circ} \mathrm{N}, 0.11259^{\circ} \mathrm{W}\right)$ from November 2010 to March 2011. Different varieties of cyclamen (Cyclamen persicum) were grown from November 2010 to January 
2011 with a density of 4 pots by square meter, and potted Hydrangeas (Hydrangea macrophylla, also several different varieties) were placed in the greenhouse at the end of January till the end of our experiment (5 pots by square meter). In both cases, the pots were watered by capillarity via a mat placed on the concrete ground. The irrigation interval varied over the experiment ranging from every 4 days in November to every day in March.

\subsubsection{Heating system}

The main heating system of the greenhouse was a heating ground system: hot water plastic tubes were placed in a concrete screed. Additional air heaters were installed and activated when the heating floor could not maintain the temperature set point. The daily mean temperature in the greenhouse was set to $16^{\circ} \mathrm{C}$. Both heating systems were fed by hot water produced by a heating oil boiler.

To monitor the heating systems operation as well as the heat inputs in the greenhouse, the input and output water temperatures were recorded for both the heating floor and the air heaters (Pt100, TConline, France). The energy consumption for ground heating was calculated using the water temperature at the inlet and outlet, along with the flow rate of the water circulation pump. The power released by the low temperature heating system $\left(P_{L T}\right)$ may be written as:

$$
P_{L T}=\dot{m}_{w} C p_{w}\left(T_{\text {in }}-T_{\text {out }}\right)
$$

where $C p_{w}=4180 \mathrm{~J} \mathrm{~kg}^{-1}$ is the water specific heat capacity, and $T_{\text {in }}$ and $T_{\text {out }}$ are the inlet and outlet water temperature respectively. Due to the thermal dissipation in the system, the transferred heat was neglected when $T_{\text {in }}-T_{\text {out }}$ was inferior to $2^{\circ} \mathrm{C}$. The mass flow rate of water passing through the heating system, $\dot{\mathrm{m}}_{\mathrm{w}}$, was calculated from the pump electric power alimentation using a linear relation between power consumption and flow provided by the pump manufacturer, with a maximum flow rate of the heating system of $39.45 \mathrm{~m}^{3} \mathrm{~h}^{-1}$. Moreover, the heat flux between the soil and the greenhouse air was measured with two heat flux sensors $(100 \times 100 \mathrm{~mm}$ sensor, Captec, France) to determine the heat input from the floor heating system.

\subsection{Dehumidifying heat pump}

\subsubsection{Experimental setup}

Previous studies have shown that the elimination of water condensation can be achieved for an acceptable cost using a dehumidifying heat pump (Boulard et al., 1989; Campen et al., 2003; Adams et al. 2009). A dehumidifying heat pump operates by retrieving latent heat at the evaporator that is maintained colder than the air dew temperature. After passing through the evaporators, the initial air (noted 1 on Figure 1) thus becomes colder and dryer ( 2 on Figure 1). The latent heat of the condensed vapour is then given back on sensible form at the condenser, resulting in the heating of the air. As the reheating of the air occurs only on sensible form, the final air ( 3 on Figure 1) is both dryer and warmer than the initial one. As the crop continues to transpire (especially if the relative air humidity decreases in the greenhouse), the machine must be powerful enough to balance the transpiration and keep a safety margin on the water content to avoid condensation. Indeed, further air dewatering was balanced by an increase of the transpiration and the dehumidification cost increased (Boulard et al., 1989). 
The heat pump dehumidifier retained here was a prototype unit manufactured by the ETT Company. The machine was specifically designed to remove water vapour from moist air using two identical electrically driven refrigeration cycles. The thermodynamic cycle of the air was the same as the one described on Figure 1. The chosen installation was a dehumidification heat pump that could condense 32 litres by hour with a ventilation flow of $10000 \mathrm{~m}^{3} \mathrm{~h}^{-1}$, for a greenhouse of $2355 \mathrm{~m}^{2}$ and a volume of $9280 \mathrm{~m}^{3}$.

To assess the operation of the dehumidifying heat pump, air temperature and relative humidity at the inlet and the outlet of the machine were measured using shielded and ventilated sensors (Vaisala HMP45C, Vaisala, Finland). The energy consumption of the heat pump compressors as well as the overall consumption of the system including control and ventilation apparatus were measured by electricity meters (DIRIS A20, Socomec, France). The condensed water flux was also measured by a tipping-bucket water fluxmeter (pluviometer 7852 , CIMA Technologie, France).

Air was sucked in at $3 \mathrm{~m}$ above the ground and driven towards the heat pump. The warm and dry air was then injected using eight polyethylene (PE) ducts at $3 \mathrm{~m}$ above the ground (Figure 2). The dry and heated air was forced through the tubes and distributed in the greenhouse by holes perforated in the PE. The mean output air velocity through the holes was measured to be $\mathrm{v}=13.6 \mathrm{~m} \mathrm{~s}^{-1}$ using a hot wire anemometer (type GGA-35, ALNOR, Finland), with a total variation of 7\% between the first and last hole along a duct. This involves that the part of the greenhouse closer to the heat pump had a higher air renewal rate than the farther end of the greenhouse. We considered the differences to be acceptable for the aim of this study based on the overall efficiency of the prototype.

As the ducts were approximately $500 \mathrm{~mm}$ in diameter, the total horizontal surface of the ventilation system was of the order of $190 \mathrm{~m}^{2}$, or 8 percent of the total greenhouse surface. However, to limit the shadowing effect, the ducts were deflated during the day when the heat pump was off. Moreover, as the greenhouse cover film was opalescent, the effects of the ducts on the radiation reaching the crop were limited.

\subsubsection{Control}

As the dehumidifying heat pump was designed to avoid condensation on plants in place of the classical ventingheating procedure, it was turned on when the greenhouse openings were closed and when the Vapour Pressure Deficit (VPD) of the air inside the greenhouse became lower than $3 \mathrm{hPa}$ (Migeon, Pierart, Lemesle, Travers \& Chassériaux, 2012). The use of a VPD set point in place of a relative humidity set point was due to the better robustness of this climatic parameter with respect to temperature changes. The adopted value was a security margin to ensure that no condensation would occur at the end of the day. Indeed, the inside temperature then remained high, with an elevated air humidity ratio, but due to the reduction of the exterior temperature at sunset, an important amount of vapour should be eliminated from the inside air before it condenses. For that reason, and in order to anticipate this problem, the VPD evolution rate (VPD slope) was also considered for an advanced start-up of the dehumidifying heat pump in order to anticipate temperature decrease at sunset. The chosen values were selected based on the results of trial and error testing during the seasons previous to this study.

Accordingly, at sunrise the crop transpiration started up as soon as the solar radiation was sufficient, but at that time, the air was still cold, involving condensation risk. For that reason, the dehumidifying heat pump could remain active after the VPD reached $3 \mathrm{hPa}$, depending on the vapour pressure deficit evolution rate. 
The compressor efficiency of the heat pump was calculated by considering that the air, of which properties were measured at the inlet, was first cooled to its dew point and then followed the saturation curve until it left the exchanger (point 2 on Figure 1). The power exchange at the evaporator, denoted $\mathrm{P}_{\text {evap}}$, was then defined as:

$$
P_{\text {evap }}=-\frac{q_{v}}{v_{3}}\left(H_{2}-H_{1}\right)
$$

Where $q_{v}$ is the air volumetric flow rate $\left(\mathrm{m}^{3} \mathrm{~h}^{-1}\right)$ through the heat pump, $\mathrm{H}_{1}$ and $\mathrm{H}_{2}$ are the air enthalpies $\left(\mathrm{kJ} \mathrm{kg}^{-}\right.$ $\left.{ }_{\text {dry air }}\right)$ at points 1 and 2 on Figure 1 , and $v_{3}$ is the specific volume $\left(\mathrm{m}^{3} \mathrm{~kg}^{-1}\right.$ dry air $)$ at point 3 . The sensible heat retrieved from the air, denoted $\mathrm{P}_{\text {sens }}$, was calculated using a classical heat balance on the dry air (subscript " $d a$ ") and the residual water vapour (subscript " $v$ ") using their specific heat (Cp):

$$
P_{\text {sens }}=-\frac{q_{v}}{v_{3}}\left(C p_{d a}+r_{2} C p_{v}\right)\left(T_{2}-T_{1}\right)
$$

The air is then reheated at the heat pump condenser. The power exchange at the condenser, $P_{\text {cond }}$, may be written as:

$$
P_{\text {cond }}=-\frac{q_{v}}{v_{3}}\left(H_{3}-H_{2}\right)
$$

The compressor efficiency $\mathrm{e}_{\mathrm{T}}$ was then calculated using $\mathrm{P}_{\text {comp }}$ (power used by the compressor) by:

$$
e_{T}=-\frac{P_{\text {cond }}}{P_{\text {comp }}}=\frac{P_{\text {cond }}}{P_{\text {evap }}+P_{\text {cond }}}
$$

The overall efficiency of the installation (denoted $\mathrm{e}_{\mathrm{o}}$ ) including the electric consumption of the auxiliary devices of the heat pump and of the ventilation system is relevant to compare different dehumidifying installations. It is defined as:

$$
e_{o}=-\frac{P_{\text {cond }}}{P_{\text {elec }}}
$$

The condensed water mass $\left(\mathrm{m}_{\text {cond }}\right)$ was calculated from the difference between the humidity ratio at the inlet and at the outlet. Measurements were recorded every 10 minutes and the mass of water condensed on the time step was calculated according to:

$$
m_{\text {cond }}=\frac{q_{3}}{v_{3}}\left(r_{1}-r_{3}\right) \cdot \Delta t
$$

with $q_{3}$ the mean air volumetric flow rate through the heat pump during a 10 minutes time step (noted $\Delta \mathrm{t}$ ), evaluated at the dehumidifier outlet. 


\subsection{Climate measurements}

\subsubsection{Outdoor climate}

To determine the influence of the outdoor climate on the greenhouse energy consumption, the outdoor conditions were monitored. Moreover, to estimate the energy consumption of venting-heating dehumidification, the outdoor air properties must be known.

A meteorological station was placed above the greenhouse roof to monitor the exterior climate. It recorded the temperature and relative humidity of the air with HMP45C sensors (Vaisala, Finland). The wind speed was measured using a cup anemometer (HA 430A, Geneq Inc., Canada), and its direction was recorded using a wind vane (W 200 P, Campbell Scientific Ltd, UK). The solar radiation was also measured with a pyranometer (CM3, Kipp \& Zonen, The Netherlands).

Given the air temperature the saturation vapour pressure $P_{v \text { sat }}$ can be determined following Nadeau and Puiggali (1995):

$$
P_{v \text { sat }}=\exp \left\{23.3265-\frac{3802.7}{\mathrm{~T}+273.18}-\left(\frac{472.68}{\mathrm{~T}+273.18}\right)^{2}\right\}
$$

Combined with the relative humidity, it was used to determine the dew temperature $T_{\text {dew }}$ and the air humidity ratio $r$ :

$$
\begin{aligned}
T_{\text {dew }} & =-273-\frac{5120}{\ln \left(\frac{\varphi}{100} \cdot \frac{P_{v \text { sat }}}{10^{5}}\right)-13.73} \\
r & =0.622 P_{\text {v sat }} \frac{\varphi / 100}{P_{\text {atm }}-P_{\text {vsat }} \frac{\varphi}{100}}
\end{aligned}
$$

\subsubsection{General climate in the greenhouse}

To quantify the climate inside the greenhouse and thus the influence of the heat pump on the greenhouse air, temperature and relative humidity were recorded at four vertical positions at 0.47, 1.92, 3.37 and 4.82 meter high (Figure 3) in the middle of the greenhouse (shaded square on Figure 2) using shielded and ventilated sensors (Vaisala HMP45C, Vaisala, Finland). Moreover, a pyranometer recorded the solar radiation at the crop level (CE 180, CIMEL, France), and the total radiative thermal exchange was measured by a net radiometer (REBS, Campbell scientific, USA).

\subsubsection{Microclimate and evapotranspiration}

In order to assess the condensation on the crop, the microclimate inside the canopy was recorded in the middle of the greenhouse (shaded square on Figure 2) at two heights by measuring air temperature and relative humidity inside the crop (Vaisala HMP45C, Vaisala, Finland). The lower sensor was placed at 11.5 or $12 \mathrm{~cm}$ above the surface depending on the pot height. The upper one was placed at $25 \mathrm{~m}$ above the surface for cyclamens crop (top of the canopy from 26 to $36 \mathrm{~cm}$ above the surface) and for Hydrangeas crop (top of the canopy from 34.5 to $42 \mathrm{~cm}$ above the surface). The leaf temperatures were also measured at the upper, middle and lower parts of the 
plants by two thermocouples for each level. These measurements made it possible to assess the occurrences of condensation on the crop (Figure 3).

The evapotranspiration (ET) was measured using a specially designed scale. Ten plants were placed on the balance tray $\left(\mathrm{S}_{\text {tray }}=2 \mathrm{~m}^{2}\right)$. A tension weighing load cell measured the water loss by evapotranspiration. The mat plant watering system was the same on the balance and on the ground. As the mat was wetted for irrigation, the measured weight was subjected to important variations, and the water evaporation remained important for approximately an hour. Corresponding points were then dropped from the analysis.

The weight loss $(\Delta \mathrm{m})$ between two time steps ( $\mathrm{t}$ and $\mathrm{t}+\Delta \mathrm{t})$ was linked to ET using the enthalpy of vaporization $\Delta \mathrm{H}_{\mathrm{v}}$ :

$$
E T=-\frac{\Delta H_{v} \cdot \Delta m}{S_{\text {tray }} \cdot \Delta t}
$$

All the measurements were recorded on one-minute intervals, but due to their large number and the duration of the experiment, they were averaged (or summed over 10-min periods) by the data loggers before storing.

\section{Results}

\subsection{Climate and microclimate characteristics, evapotranspiration}

Climate homogeneity inside the greenhouse was assessed during a previous study (Migeon et al., 2012), and it was shown that neither significant temperature nor humidity vertical gradients appeared (over the canopy) during the heat pump operation. This seems due to the air mixing induced by the air jet coming out from the holes of the PE ducts. Conversely, during the day, when the heat pump did not operate, a vertical temperature gradient was established with a $1.5^{\circ} \mathrm{C}$ difference between the lowest and highest measurement points.

Concerning the microclimate inside the crop, results are displayed in Figure 4. As expected, the diurnal conditions were safe from condensation risk, but at the end of the day, the leaf temperatures decreased toward the dew temperature, that is the temperature at which the water vapour of the air could condense on the leaves. By retrieving the water vapour from the greenhouse air, the heat pump operation limited the increase of the dew temperature and no observed leaf was cold enough for the vapour to condense on it. During the night, the dehumidifier stabilised the dew temperature while the heating of the greenhouse stabilised the leaf temperature, ensuring that no condensation occurred. This was confirmed by visual inspections conducted by the producer who did not observe any plant infected by Botrytis Cinerea.

\subsection{Dehumidifier operation}

As stated, the dehumidification heat pump was designed to balance the night evapotranspiration of the crop, as the low temperature during the night was the most prone to induce condensation. Figure 5 displays the measured evapotranspiration during one night in March along with the condensed water by the heat pump and its operating period. It can be seen that during the night, evapotranspiration was balanced by condensation at the heat pump. During operation, the condensation rate was around $12 \mathrm{~W} \mathrm{~m}^{-2}$ (or $\left.45 \mathrm{~h} \mathrm{~h}^{-1}\right)$ for the considered period. Significant variations of the evapotranspiration or condensation by heat pump occurred depending on the air temperature and relative humidity. These variations involved changes of the heat pump operation and efficiency. 
Measurements indicate that the average electrical power of the two compressors was $\mathrm{P}_{\text {comp }}=7.62 \mathrm{~kW}$ and the total electric power required by the machine was $\mathrm{P}_{\text {elec }}=10.23 \mathrm{~kW}\left(4.4 \mathrm{~W} \mathrm{~m}^{-2}\right)$. Consequently, it was deduced that the power dissipated by the ventilation fan and accessories was approximately $2.61 \mathrm{~kW}$. During heat pump operation, the average power exchanged at the condenser was $P_{\text {cond }}=-48.7 \mathrm{~kW}$ (deduced from Eq. 4), and $P_{\text {evap }}$ $=41.1 \mathrm{~kW}$ (deduced from Eq. 2) at the evaporator, $57 \%$ of which corresponded to the latent heat generated from water vapour condensation. Along with the electric consumption, these data made it possible to calculate the thermodynamic and the overall efficiencies of the heat pump during its operation, as displayed in Figure 6 for March $20^{\text {th }}$ and $21^{\text {th }}$. On this graph, the compressor efficiency (Eq. 5) was approximately $\mathrm{e}_{\text {comp }}=7.5$ and the overall efficiency (Eq. 6) $e_{o}=5$. As stated before, those values depend on the operating condition, mostly the greenhouse air properties. For the entire experiment from November the $1^{\text {st }}$ to April the $1^{\text {st }}$, the mean values for thermodynamic and overall efficiency were $\mathrm{e}_{\text {comp }}=8$ and $\mathrm{e}_{\mathrm{o}}=4.9$ respectively.

\subsection{Heating operation}

The energy consumption for ground heating was calculated using Eq. 1. However, the energy lost by the buried hot water tube was not entirely transferred to the greenhouse air, as a significant part heated the soil downward and between the tubes and the soil surface. In order to estimate the heat flux from the soil to the greenhouse air $\left(\mathrm{P}_{\text {soil }}\right)$, the heat flux measurements from two flux meters were averaged to get an estimation of heat flux.

Moreover, the dehumidifier not only condensed water vapour but also transferred a significant amount of sensible heat to the greenhouse air (Eq. 3). When the cold air passed through the evaporator it was first cooled, leading to vapour condensation. Latent heat was then transferred from the water to the heat pump system. A significant amount of heat was also retrieved from the dry air and the residual water vapour. At the condenser, the heat transferred from the heat pump to the air was entirely sensible heat. Thus, apart from the condensation involved by latent heat, the sensible heat balance should be considered in order to estimate the heating contribution of the dehumidifier in the overall greenhouse heating system. Figure 7 displays the heat flux transferred to the greenhouse by the ground heating system, the associated energy consumption for water heating (named heat floor consumption) and the heat pump sensible contribution for seven consecutive days in March. It can be seen that the heating system was only used at night, for an output power between 100 and $175 \mathrm{~W} \mathrm{~m}^{-2}$. Obviously, for winter conditions the ground heating period was much longer with a continuous operation at the end of November. Part of this energy was lost for the greenhouse heating, which explains why the effective heat flux input in the greenhouse (heat floor contribution in Figure 7) was much lower. The differences between the two values was due to the heat flux downward from the hot tubes that heated the soil below, and the energy needed to heat the soil between the tubes and the soil surface before heat could reach the greenhouse. Consequently, when the ground heating system operated at full capacity, only a small part of the energy consumed to produce hot water was used to heat the greenhouse. For the entire investigated period, the mean utilisation ratio was of the order of 0.5 , meaning that half the energy consumed (i.e., gas consumption) was lost.

Moreover, one can see that the heat flux between the soil and the greenhouse air was decoupled from the flux out of the hot water tubes. Indeed, the soil was heated by solar radiation during the day (negative flux in Figure 7) and part of the energy was given back to the greenhouse at the beginning of the night.

Also observable from Figure 7, the heat pump contribution to greenhouse heating is lower than that of the ground heating system. However, for instance during the first part of the night between March $25^{\text {th }}$ and $26^{\text {th }}$, the 
heat pump contribution, with the heat destocking from the soil, was sufficient to delay the ground heating operation up until midnight. Such a situation of a warm night following a warm day was usual during spring and in this case a limited ground heating input was needed. It was also observed that the dehumidifying heat pump sometimes transferred enough energy to the greenhouse to maintain the temperature above the set point of $16^{\circ} \mathrm{C}$ without requiring the use of the greenhouse heating system (for instance from March $23^{\text {rd }}$ to $25^{\text {th }}$ ).

When complementary ground heating input was necessary, its use was limited thanks to the heat pump. Figure 8 displays the part of the heat pump energy input to the total greenhouse heating input (soil flux and heat pump sensible contribution) during the experiment together with the daily mean exterior temperature. It must be stated that due to experimental difficulties, the ground flux was not always available. However, one can see that the heat pump contribution was between 10 and $40 \%$ of the total heat input. If the total needs were important, as was the case most of the time in November when temperatures were low, the heat pump contribution was reduced due to the heavy use of the ground heating system. At the end of March the exterior mean temperatures were higher, the total heating requirements were lower and the heat pump contribution was proportionally higher.

\section{Discussion}

The heat pump contribution to the greenhouse heating was crucial, as it significantly reduced the ground heating system use, and therefore the natural gas consumption. Thus, when discussing the efficiency of the various dehumidification methods, one needs to take the heating contribution of the dehumidifier into account.

\subsection{Total energy consumption}

In the condition described here, the total energy consumption was the sum of the natural gas consumption for the base heating of the greenhouse (ground heating) and the electric consumption of the heat pump. These consumptions depended on the outdoor climate (both the temperature and humidity) and on the temperature set point, as depicted in Figure 9. However, if the consumption for greenhouse heating strongly depended on the exterior climate, the power needed by the dehumidifier hardly varied with the exterior conditions. Indeed, it operated only on the inside air, contrary to the dehumidifying procedures that involve air renewal with exterior air. Hence, large variations of the power required for dehumidification may be expected in the case of the venting heating and air heat exchanger procedure.

\subsection{Comparison with venting heating}

By using the simple venting-heating procedure, supplementary heating needs due to the vent opening, denoted $Q_{\text {venting, }}$ occurs. The method used to estimate the heat losses induced by the venting-heating process is described in Appendix A, leading to the value on a time step:

$$
Q_{\text {venting }}=m_{\text {cond }} \frac{H_{i}-H_{e}}{r_{i}-r_{e}}
$$

Where $Q_{\text {venting }}$ represents the heat losses specific to the venting and thus the supplementary heating needs. When added to the value of the dehumidifier sensible heat input, this gives the total heat input differences between venting heating and thermodynamic dehumidifier.

As described before, not all the energy used for ground heating ultimately heated the greenhouse, and a large part was lost. As other heating devices could be used with lower to no heat loss, $Q_{\text {venting }}$ must be seen as the 
lower bound for the supplementary gas consumption to be provided. In the following, we therefore underestimate the total energy consumption by a factor that depends on the heating system used.

The corresponding different energy consumptions are displayed on Figure 10 along with the energy consumption ratio of the natural gas estimated consumption by venting-heating to the measured electricity consumption by the heat pump. The electrical consumption of the heat pump remained stable but the base heating gas consumption strongly depended on the daily climate. The calculated gas consumption for venting-heating (square symbols) had an intermediate behaviour as the dehumidification needs were more stable, even if it also depended on the exterior conditions. The dehumidification ratio (round symbols) is the ratio between the calculated gas consumption for dehumidification by venting-heating and the measured electrical consumption for the same day. The ratio is comprised between 6 and 8.5, meaning that in order to obtain the same dehumidification, the venting-heating method would require 6 to 8.5 times more energy than the present heat pump. The ratio was all the more important, as the exterior temperature was higher. Indeed, for high exterior temperatures, the sensible heat pump heating contribution was proportionally higher. Due to the compressor efficiency being superior to 1 , this involved a more important decrease of the overall energy consumption.

As the thermodynamic dehumidifier required less energy than the venting-heating procedure, the operating cost of the dehumidification was lower. However, the investment cost for a large heat pump could be significant, contrary to the venting heating procedure, which only requires more natural gas consumption for an existing installation.

\subsection{Comparison with venting heating using a heat exchanger}

The principle is here the same as in the previous paragraph, but a heat exchanger is placed in the path of the input air in order to retrieve heat from the outgoing air. The calculation of the involved heat losses is provided in Appendix B, leading to the supplementary energy needs $Q_{\text {exch }}$ :

$$
Q_{\text {exch }}=\frac{m_{\text {cond }}}{r_{i}-r_{e}}\left(H_{i}-\min \left(H_{e}+H_{i}-H_{i}^{\prime} ;\left(C p_{d a}+r_{e} C p_{v}\right) T_{i}\right)\right)
$$

As for classical venting-heating, this quantity represents the supplementary heating required for the dehumidification of the greenhouse. In order to evaluate the entire energy needs to replace the heat pump, the sensible heat contribution of the heat pump must be added to $Q_{\text {exch. }}$.

An estimation of the operational energy cost of the venting heating with the air exchanger can then be made. It should be noted that the energy consumption for the ventilation (mandatory to use a heat exchanger) was not taken into account in this study. Moreover, like for classical venting-heating method, $Q_{\text {exch }}$ was assumed equal to the energy consumption, providing the lowest estimation of the total natural gas consumption.

Figure 11 displays the energy consumptions for heat pump dehumidification and venting-heating with an exchanger along with the energy consumption ratio. As for the classical venting-heating method, the total consumption was several times larger than for the dehumidifying heat pump. Thanks to the heat exchange, the consumption was, however, smaller than with the classical venting-heating and the energy consumption ratio was between 3 and 8 . 
In order to discuss the opportunity to use a heat pump as dehumidifier, the operational cost must be assessed as well as the investment cost and depreciation. In this paper we only investigate the operational costs of the proposed apparatus in order to compare them to the operational costs of classical dehumidification methods. The comparisons serve two purposes: on the one hand, they define the operational conditions when dehumidification is more efficiently done with a heat pump and when it is not, providing some dehumidification strategy elements; on other hand, they give an operational cost to include in a proper economic analysis along with investment and depreciation costs. Indeed, as investment costs strongly depend on the effective horticultural system (plant needs and climate), such analysis goes beyond the scope of the present study.

\subsubsection{Variations of the energy consumption ratio}

Figure 12 displays the daily energy consumption ratio depending on the difference of mean air enthalpy inside and outside the greenhouse for both cases: venting-heating and venting-heating with heat exchanger. The energy consumption ratio for both venting heating method either remained stable or increased with the air enthalpy difference. Indeed, as the inside air was replaced by colder exterior air, the more energy differences there were, the more heat loss. As heat was retrieved from the inside air in the case of a heat exchanger, the heat loss was lower in this case, as depicted by the lower energy consumption ratio on Figure 12. However, for high differences of air enthalpy, the energy ratios tended to the same value as they corresponded to cold outside temperature, where the sensible heat input of the thermodynamic dehumidifier was more important. Thus, heat recovering accounted for only a small fraction of the overall needs, and the energy consumption ratio differences between the two methods decreased. The influence of the air humidity ratio inside and outside the greenhouse on the energy consumption ratios is displayed on Figure 13. The energy consumption ratios increased with the difference of water contents. Indeed, for more or less constant interior air conditions (controlled temperature and relative humidity), large humidity ratio differences corresponded to situations for which exterior air had a low humidity ratio, and thus a low temperature. In such conditions, the heat losses were important in the case of ventilation, needing a high energy consumption to restore the greenhouse air temperature.

Overall, the heat pump energy consumption was at least 3 times lower than the energy consumption for the other dehumidification methods based on ventilation; however, using the proposed dehumidifier involved replacing the natural gas by electricity as an energy source. As the costs of these two sources are different, the operational cost should be assessed.

\subsubsection{Impact of the energy prices}

Table 1 displays the electricity and natural gas prices for selected countries, as well as the energy price ratio calculated by natural gas prices / electricity prices. A low ratio indicates that the natural gas is relatively cheap compared to electricity; a high ratio indicates that the natural gas price has a price close to the electricity one. Obviously, energy costs strongly depend on the country geographic location, energy production systems and South Korea has the highest price ratio with the lowest electricity price of the list. 
As electricity is generally more expensive than the natural gas, the energy consumption gains performed by switching from ventilation (using natural gas) to heat pump (using electricity) is limited at the cost level by the price ratio. In order for the heat pump dehumidifier to be more efficient, the product of the energy consumption ratio by the price ratio must by superior to one. The last column of Table 1 displays the minimum energy consumption ratio needed by the heat pump to be cost effective.

The energy consumption ratios depicted on Figure 12 and Figure 13 were above 6 for classical venting-heating and 3 for venting-heating with heat exchanger. Thus, for the country where the minimum energy consumption ratio displayed on Table 1 is inferior to 3, the heat pump dehumidifier is interesting from an operational cost point of view. It is the case for Japan, France, Germany and South Korea in the examples depicted on Table 1. For the country with high minimum energy consumption ratio such as Canada, the heat pump dehumidifier would be favourable only under cold conditions with high air enthalpy difference between the greenhouse and the exterior. Under such conditions, the interest of a heat pump dehumidifier installation therefore seems unlikely.

For intermediate cases, where the minimum energy consumption ratio is comprised between 3 and 4 or 4.5, the opportunities of a heat pump dehumidifier must be deeply analysed depending on the exterior climate and growing conditions. Moreover, the installation of a heat pump dehumidifier does not involve its use continuously, and the dehumidification method can be chosen according to the conditions (outside climatic conditions + inside temperature and humidity set points).

Although the present study was based on ornamental crop with a low transpiration rate and low heating needs, its conclusions could be applied to different species whose transpiration rates and heating needs are higher, such as tomato or cucumber, with a more powerful heat pump to condense more water. However, for such crops, as the heating needs would be larger, the sensible heat contribution of the dehumidifier would be less significant, reducing the economic interest of the dehumidification heat pump. Moreover, the large greenhouses used for such cultures would involve an important investment cost that would be difficult to justify.

\subsubsection{Recommendations}

As depicted on Figure 12 and Figure 13, the energy consumption ratio evolved when the outside climate changed. It appears that, for a fixed greenhouse air, the energy ratio depended on the exterior air enthalpy - and thus its temperature and humidity ratios. Thus, the measurement of air properties would give an indicator of the most efficient dehumidification procedure for actual climate. As the classical venting-heating was the most inefficient dehumidification procedure whatever the conditions, the choice was limited to venting-heating with exchanger and heat pump.

In the former case, if ground heating is efficient for base heating of a crop on the greenhouse floor, using another system to heat the air in case of venting-heating through an exchanger should be considered to limit energy waste.

The natural gas heating system remains mandatory for a greenhouse to balance high heat loss during cold winter, even if a heat pump is installed. It is then simple to switch from one dehumidification system to the other, and hence to choose the most efficient one depending on the exterior conditions. Moreover, the inclusion of weather 
forecast to greenhouse climate control automation would allow an easy use and an efficient dehumidification solution.

Further researches remain however necessary to improve the energetic efficiency of the apparatus. Indeed, the dry and hot air circulation in the greenhouse is still unknown, and some energy saving could be achieved by a proper Computational Fluid Dynamics analysis of the air circulation. Thus, a better circulation scheme could be determined to concentrate the dehumidification effects on the crop, while allowing for easy access for plants handling. Moreover, the apparatus scaling and control remain crude, and the overall efficiency would gain from a control based on accurate measurements of the VPD around the crop and of the leaf temperature: the heat pump would then be more tightly controlled to minimize the energy consumption.

\section{Conclusions}

The proposed dehumidification heat pump was designed to avoid dew point during the night by balancing the night evapotranspiration. Thanks to an anticipated operation before sunset, this strategy revealed its efficiency by effectively preventing condensation on the crop. The apparatus thus made possible the growth of sensitive crops that would otherwise potentially be infected by fungus such as Botrytis Cinerea.

The system analysis showed that the heat input by the heat pump as a by-product of the dehumidification, was significant and could lead to a large reduction of the conventional heating used in favourable conditions. Indeed, during autumn and spring when the heating needs were reduced, the heat pump sensible heat inputs were sufficient to maintain the temperature set point, making it possible to avoid any natural gas consumption under favourable conditions.

Model comparisons with classical venting heating showed that the described device was 6 to 8.5 less energy consuming than the classical dehumidification method. Moreover, the comparison with venting-heating with an air exchanger showed that despite the heat recovery at the exchanger, the heat pump dehumidifier presented here remained 3 to 8 times less energy consuming than the greenhouse ventilation.

The operational cost gains of this dehumidification approach depend on the relative cost of electric and fossil energy, suggesting that the presented dehumidification strategy could be relevant for a number of countries. Furthermore, dehumidification could be obtained by using the most cost efficient method at a given time, either the described system or by the venting-heating, depending on the operating conditions and the associated heating requirement.

Further researches remain needed to optimize the apparatus, particularly the dry and hot air ventilation system and the control of the heat pump. At last, a complete cost analysis of the system should also be conducted to incorporate the cost of the heat pump in order to perform a thorough economic study

\section{Acknowledgements}

This project was initiated by VEGEPOLYS, French competitive cluster, Angers, France with funding from ADEME and Pays de Loire Region. The authors thank Dominique Lemesle and Alain Travers for the set-up of the experimental devices as well as Chauvin Production, ETT, and ARIA companies.

\section{Reference}

Adams, S., Langton, A., \& Plackett, C. (2009). Energy management in protected cropping: Humidity control (Factsheet No. Factsheet 07/09) (p. 12). HDC. http://www.hdc.org.uk/publication/energy-management- 
protected-cropping-humidity-control. Accessed on: 2/27/2014

Bakker, J. C. (2009). Energy saving greenhouses. Chronica Horticulturae, 49(2), 19-23.

Boulard, T., Baille, A., Lagier, J., Mermier, M., \& Vanderschmitt, E. (1989). Water vapour transfer in a plastic house equipped with a dehumidification heat pump. Journal of Agricultural Engineering Research, 44, 191-204. http://doi.org/10.1016/S0021-8634(89)80081-2

Campen, J. B., \& Bot, G. P. A. (2001). Design of a Low-Energy Dehumidifying System for Greenhouses. Journal of Agricultural Engineering Research, 78(1), 65-73. http://doi.org/10.1006/jaer.2000.0633

Campen, J. B., Bot, G. P. A., \& de Zwart, H. F. (2003). Dehumidification of greenhouses at northern latitudes. Biosystems Engineering, 86(4), 487-493. http://doi.org/10.1016/j.biosystemseng.2003.08.008

Campen, J. B., Kempkes, F. L. K., \& Bot, G. P. A. (2009). Mechanically controlled moisture removal from $\begin{array}{llll}\text { greenhouses. } & \text { Biosystems } & \text { Engineering, }\end{array}$ http://doi.org/10.1016/j.biosystemseng.2009.01.001

Chassériaux, G. (1987). Heat pumps for reducing humidity in plastics greenhouses. Plasticulture, 73, 29-40.

Chassériaux, G., \& Gaschet, O. (2009). A multifunction dehumidifying heat pump for greenhouses. Acta Hort. (ISHS), 893, 469-476.

De Halleux, D., \& Gauthier, L. (1998). Energy Consumption Due to Dehumidification of Greenhouses under Northern Latitudes. Journal of Agricultural Engineering Research, 69(1), 35-42. http://doi.org/10.1006/jaer.1997.0221

Grisey, A., Pommier, F., Chantry, N., Piasentin, J., \& Chassériaux, G. (2007). Utilisation rationnelle de l'énergie dans les serres - Situation technico-economique en 2055 et levier d'action actuels et futurs (Étude). ADEME. Retrieved from http://www.ademe.fr/utilisation-rationelle-lenergie-serres

International Energy Agency. (2013). Energy prices and taxes. Quaterly statistics First quarter 2013 (p. 423 ). www.cne.es/cgi-bin/BRSCGI.exe?CMD=VEROBJ\&MLKOB=728018434242 Accessed on 26/02/2014

Migeon, C., Pierart, A., Lemesle, D., Travers, A., \& Chassériaux, G. (2012). A deshumidifying heat pump for greenhouse. ISHS, 952, 485.

Nadeau, J.-P., \& Puiggali, J.-R. (1995). Séchage: des processus physiques aux procédés industriels. Londres, Paris, New York: Tec \& Doc Lavoisier.

Rousse, D. R., Martin, D. Y., Thériault, R., Léveillée, F., \& Boily, R. (2000). Heat recovery in greenhouses: a practical solution. Applied Thermal Engineering, 20(8), 687-706. http://doi.org/10.1016/S13594311(99)00048-4

\section{Appendix A}

By using venting heating combination, greenhouse vent are opened allowing warm and moist indoor air leaving the greenhouse. This air is replaced by cold and dry air from the exterior. For a given time step, the water vapour eliminated $m_{\text {elim }}$ is equal to:

$$
m_{\text {elim }}=\tau_{r} \frac{V}{v_{i}}\left(r_{i}-r_{e}\right)
$$

Where $\tau_{\mathrm{r}}$ is the ventilation rate, defined as the volume of the greenhouse renewed during the time step, $V$ the greenhouse volume and $r$ is the air humidity ratio in $\mathrm{kg}$ vapour by $\mathrm{kg}$ of dry air at the interior $\left(r_{i}\right)$ and the exterior $\left(r_{e}\right)$ of the greenhouse.

Replacing the warm air with colder and dryer one involves heat losses that must be balanced by more heating. The supplementary heat loss, $Q_{\text {venting }}$, on the time step can be calculated by enthalpy balance:

$$
Q_{\text {venting }}=\tau_{r} \frac{V}{v_{i}}\left(H_{i}-H_{e}\right)
$$


In order to eliminate the same quantity of water as the dehumidifying heat pump, one must have:

$$
m_{\text {elim }}=m_{\text {cond }} \Leftrightarrow \tau_{r} \frac{V}{v_{i}}\left(r_{i}-r_{e}\right)=m_{\text {cond }}
$$

Thus, the ventilation rate must be equal to:

$$
\tau_{r}=m_{\text {cond }} \frac{v_{i}}{V} \frac{1}{r_{i}-r_{e}}
$$

Replacing this expression of $\tau_{\mathrm{r}}$ in equation A.2 leads to:

$$
Q_{\text {venting }}=m_{\text {cond }} \frac{v_{i}}{V} \cdot \frac{1}{r_{i}-r_{e}} \cdot \frac{V}{v_{i}}\left(H_{i}-H_{e}\right)=m_{\text {cond }} \frac{H_{i}-H_{e}}{r_{i}-r_{e}}
$$

\section{Appendix B}

From Appendix A, the supplementary heat required to balance the venting-heating heat loss is given by:

$$
Q_{v e n t}=m_{c o n d} \frac{H_{i}-H_{e}}{r_{i}-r_{e}}
$$

630

This formulation can be used in the case of an exchanger:

$$
Q_{\text {exch }}=m_{\text {cond }} \frac{H_{i}-H^{\prime}}{r_{i}-r_{e}}
$$

631

And then:

$$
Q_{\text {exch }}=m_{\text {cond }} \frac{H_{i}-H^{\prime}}{r_{i}-r_{e}}=m_{\text {cond }} \frac{{H^{\prime}}_{i}-H_{e}}{r_{i}-r_{e}}
$$

Hence:

$$
\begin{gathered}
H_{i}-{H^{\prime}}_{e}={H^{\prime}}_{i}-H_{e} \\
\Leftrightarrow H_{e}^{\prime}=H_{e}+H_{i}-H^{\prime}{ }_{i}=H_{e}+Q_{\text {trans }}
\end{gathered}
$$


The energy needs $Q_{\text {exch }}$ can be determined by replacing $H_{e}^{\prime}$ in Eq. B 4 by its expression provided by Eq. B 6 . Then, $H_{e}^{\prime}$ must be determined from $H_{e}, H_{i}$ and $H_{I}^{\prime}$. If $H_{e}$ and $H_{i}$ can be calculated using the properties of the airs using the temperatures and water, those properties are not known for the outgoing air after the exchanger (air i'). Some assumptions must be made to determine $H_{i}^{\prime}$.

If we assume that all the recoverable energy is effectively gained by the ingoing exterior air, then: $\mathrm{T}_{\mathrm{i}}^{\prime}=\mathrm{T}_{\mathrm{e}}$.

$$
\text { 9.1. } \mathrm{T}_{\mathrm{e}}>\mathrm{T}_{\text {dew, } \mathrm{i}}
$$

If $T_{e}$ is above the dew temperature of the interior air $\left(T_{d e w} i\right)$, the outgoing air is cooled without any vapour condensation. Thus, the exchanged energy on the 10 minute time step can be determined using:

$$
Q_{\text {trans }}=H_{i}-H_{i}^{\prime}=\left(C p_{d a}+r_{i} C p_{v}\right)\left(T_{i}-T_{e}\right)
$$

Injecting Eq. B 7 in Eq. B 6 yields:

$$
H_{e}^{\prime}=H_{e}+H_{i}-H_{i}^{\prime}=H_{e}+Q_{\text {trans }}=H_{e}+\left(C p_{d a}+r_{i} C p_{v}\right)\left(T_{i}-T_{e}\right)
$$

$$
\text { 9.2. } T_{e}<=T_{d e w, ~}
$$

If the temperature of the exterior is inferior to the dew temperature of the interior air, both latent and sensible heat exchanges are involved. In this case, the final humidity ratio of the outgoing air is calculated using:

$$
r_{i}^{\prime}=0.622 P_{v \text { sat }\left(T_{e}\right)} \frac{1}{P_{a t m}-P_{v s a t}\left(T_{e}\right)}
$$

With $P_{v \text { sat }(T e)}$ is the saturation vapour pressure at $\mathrm{T}_{\mathrm{e}}$. The total heat exchange is thus the sum of:

- The cooling of the initial greenhouse air from $T_{i}$ to the dew temperature of the greenhouse air, denoted $\mathrm{T}_{\text {dew(i) }}$ :

$$
Q_{1}=\left(C p_{d a}+r_{i} C p_{v}\right) \cdot\left(T_{i}-T_{d e w, i}\right)
$$

- The latent heat of condensation of $r_{i}-r_{i}^{\prime}$ in $\mathrm{kg}$ by kilo of dry air:

$$
Q_{2}=\Delta H_{v}\left(r_{i}-r_{i}^{\prime}\right)
$$

- The cooling of the remaining water vapour and the dry air from $\mathrm{T}_{\mathrm{dew}(\mathrm{i})}$ to the final temperature $\mathrm{T}_{\mathrm{e}}$ :

$$
Q_{3}=\left(T_{\text {dew }, i}-T_{e}\right) \cdot\left[\left(C p_{d a}+r_{i}^{\prime} C p_{v}\right)+\left(r_{i}-r_{i}^{\prime}\right) \cdot C p_{\text {water }}\right]
$$

In this case, the total exchanged heat is: 


$$
\begin{aligned}
Q_{\text {trans }}=Q_{1}+Q_{2} & +Q_{3} \\
& =\left(C p_{d a}+r_{i} C p_{v}\right) \cdot\left(T_{i}-T_{d e w, i}\right)+\Delta H_{v}\left(r_{i}-r_{i}^{\prime}\right) \\
& +\left(T_{d e w, i}-T_{e}\right)\left[\left(C p_{d a}+r_{i}^{\prime} C p_{v}\right)+\left(r_{i}-r_{i}^{\prime}\right) \cdot C p_{\text {water }}\right]
\end{aligned}
$$

and

$$
\begin{aligned}
H_{e}^{\prime}=H_{e}+Q_{\text {trans }} & \\
& =H_{e}+\left(C p_{d a}+r_{i} C p_{v}\right) \cdot\left(T_{i}-T_{d e w, i}\right)+\Delta H_{v}\left(r_{i}-r_{i}^{\prime}\right) \\
& +\left(T_{d e w, i}-T_{e}\right)\left[\left(C p_{d a}+r_{i}^{\prime} C p_{v}\right)+\left(r_{i}-r_{i}^{\prime}\right) \cdot C p_{\text {water }}\right]
\end{aligned}
$$

656 The final temperature of the ingoing air cannot rise above the inside temperature, otherwise heat would be exchanged from the ingoing to the outgoing air. To depict this limit, and finally:

$$
H_{e}^{\prime}=\min \left(H_{e}+Q_{\text {trans }} ; H_{e}+\left(C p_{d a}+r_{e} C p_{v}\right) \cdot\left(T_{i}-T_{-} e\right)\right)
$$
where $Q_{\text {trans }}$ is calculated either by Eq. B 7 or B 13 depending on the case. 


\section{List of figures}

661

Figure 1: Air flow in a dehumidifying heat pump and associated air properties evolution during its treatment. Figure 2: Left: air flow diagram; right: three-dimensional representation of the air flows. The square represents the measurements point localizations, the grey lines the plastic ducts.

Figure 3: Schematic view of the experimental set-up with measurement positions.

Figure 4: Evolution of the leaf and dew temperatures in the cover. For each time step, only the lowest and highest leaf temperature are displayed, whatever the position.

Figure 5: Evolution over time of the condensed vapour by the dehumidifier and crop evapotranspiration (March $\left.20^{\text {th }}-21^{\text {st }}\right)$.

Figure 6: Hourly mean compressor $\left(e_{\text {comp }}\right)$ and overall $\left(e_{o}\right)$ efficiency.

Figure 7: Ground heating and heat pump heat input and ground heating system consumption from March $19^{\text {th }}$ to $26^{\text {th }}$.

Figure 8: Part of the heat pump contribution to the total daily energy input (bar) and exterior temperature (line). Figure 9: Energy consumptions of the greenhouse heating systems.

Figure 10: Comparison of energy consumptions between heat-pump dehumidifier and venting heating.

Figure 11: Comparison of energy consumptions between heat-pump dehumidifier and venting heating method using a heat exchanger.

Figure 12: Daily energy consumption ratio according to enthalpy differences between inside an outside airs.

Figure 13: Daily energy consumption ratio according to air humidity ratio differences between inside and outside airs.

Figure 14: Notation for airs passing through air exchanger.

\section{List of table}

Table 1: Energy prices for industry in some OECD country and corresponding energy consumptions ratio for operational cost equivalence. 2011 charged prices except otherwise stated (International Energy Agency, 2013). 


\section{Figure 1}

greenhouse moist air
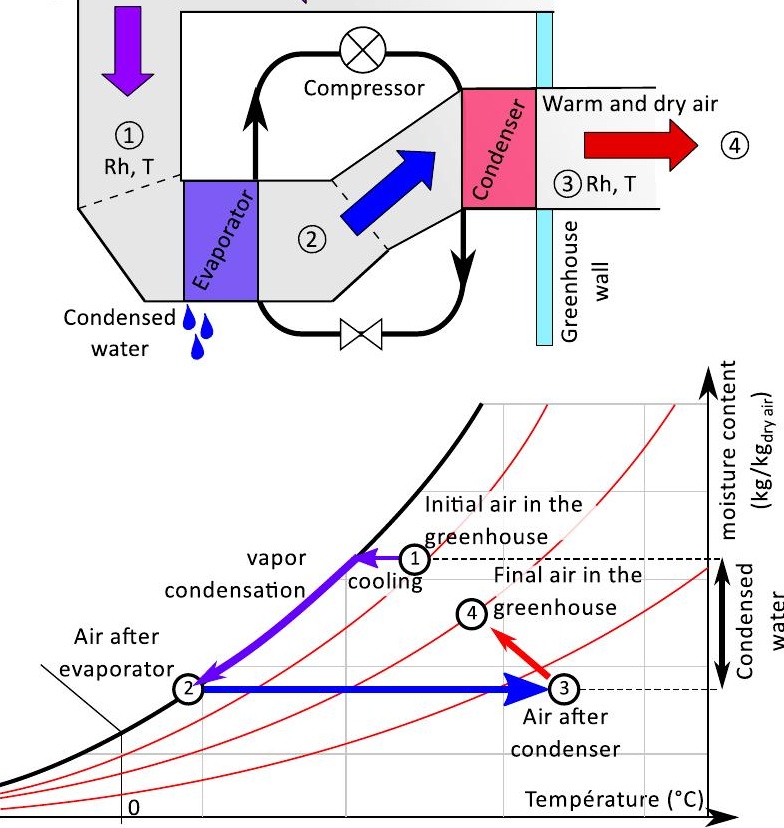


\section{Figure 3}

\section{central mast for}

vertical homogeneity

$4.82 \mathrm{~m} \uparrow \mathrm{T}_{\mathrm{a}}, \varphi$

$3.37 \mathrm{~m} \mathrm{~T}_{\mathrm{a}}, \varphi \quad \mathrm{T}_{\mathrm{a}}^{\mathrm{T}_{\mathrm{a}} \infty \varphi}$

$1.92 \mathrm{~m} \uparrow \mathrm{T}_{\mathrm{a}}, \varphi$

centr

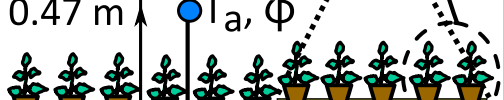
a日

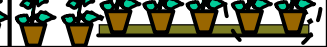




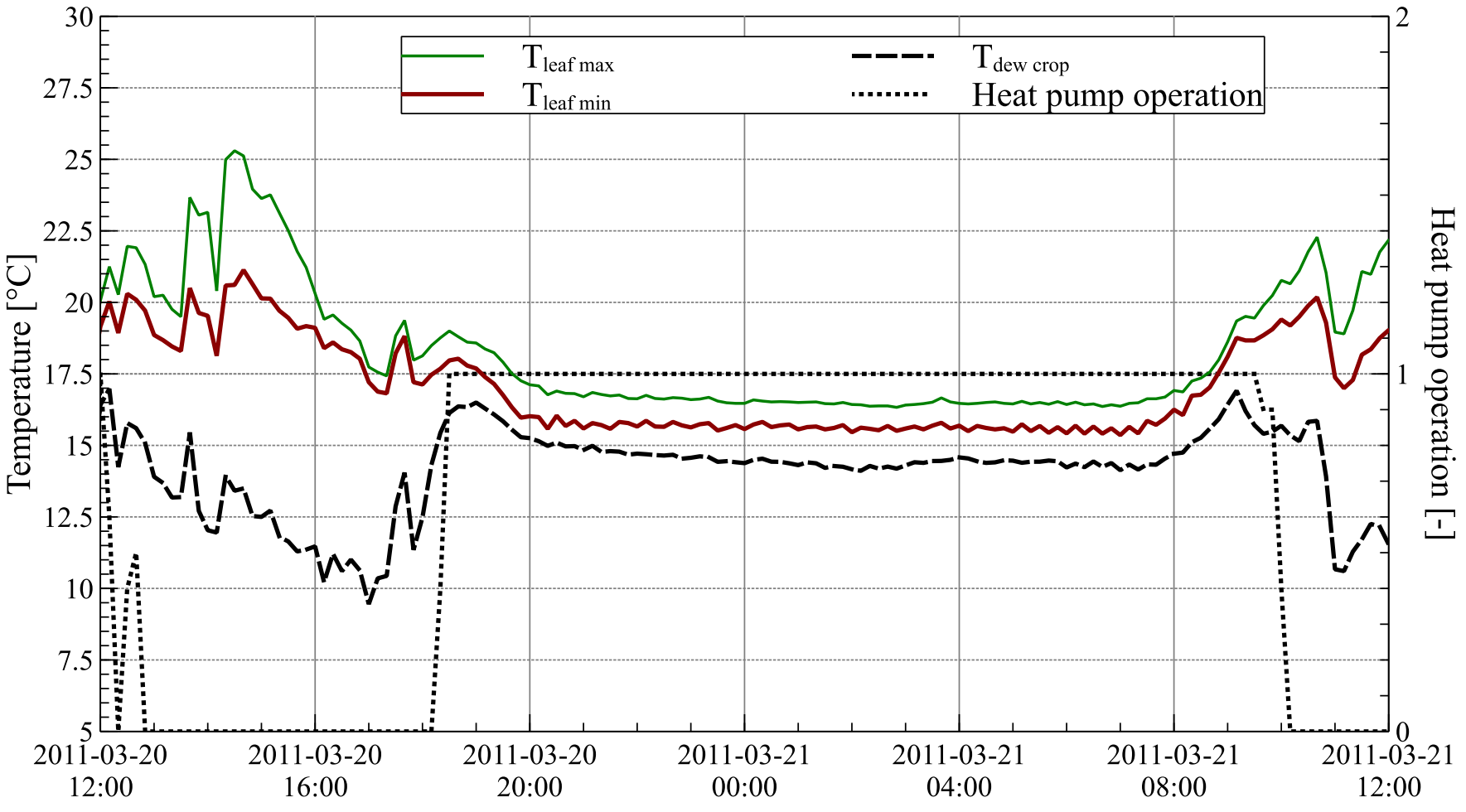




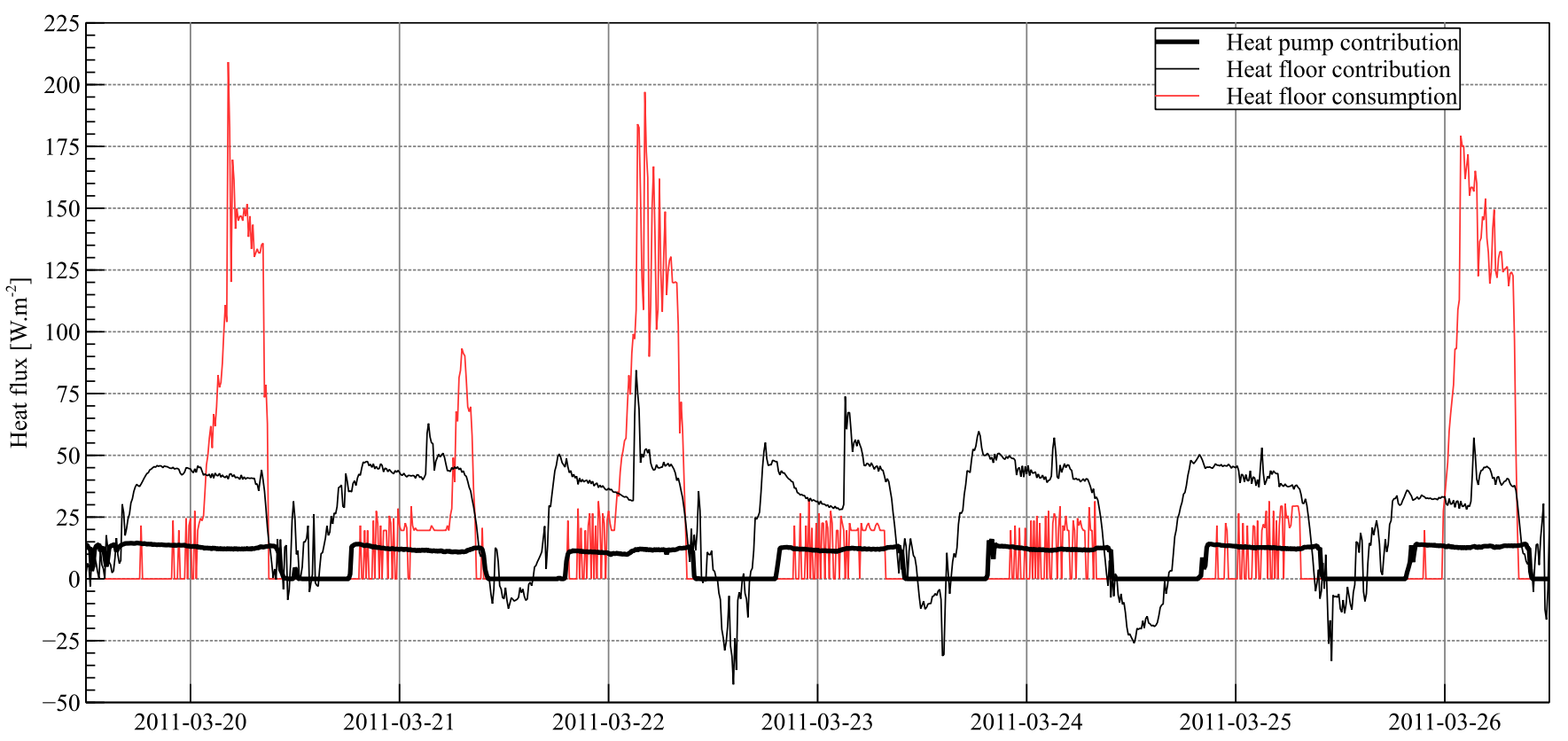





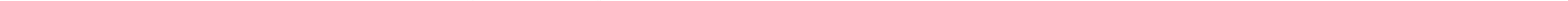




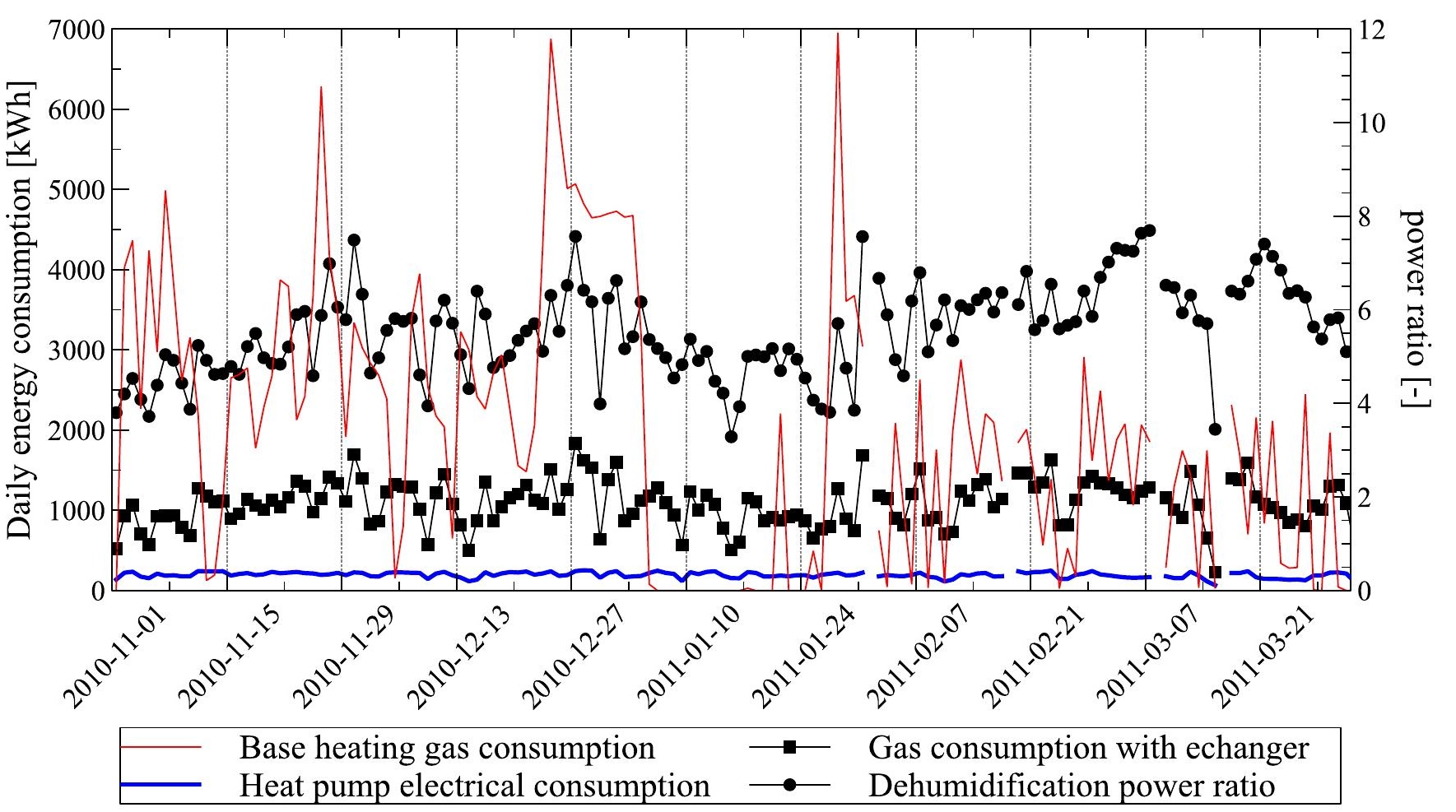




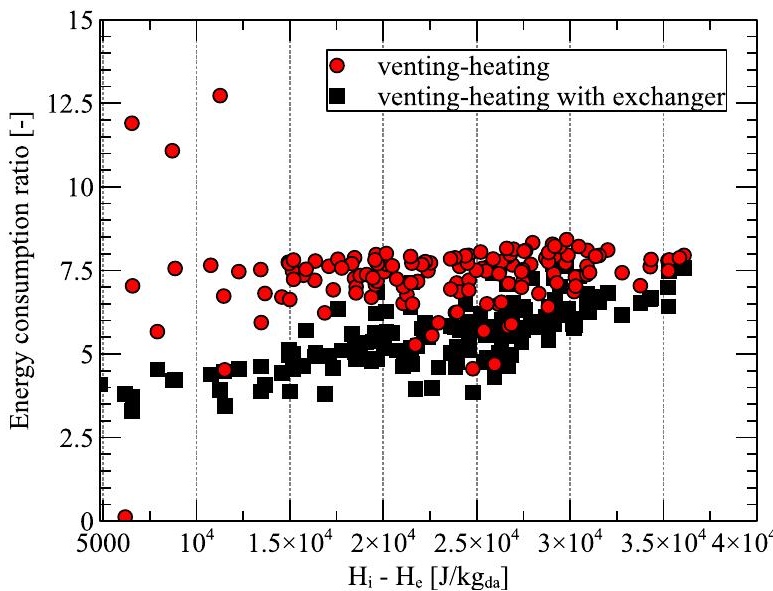




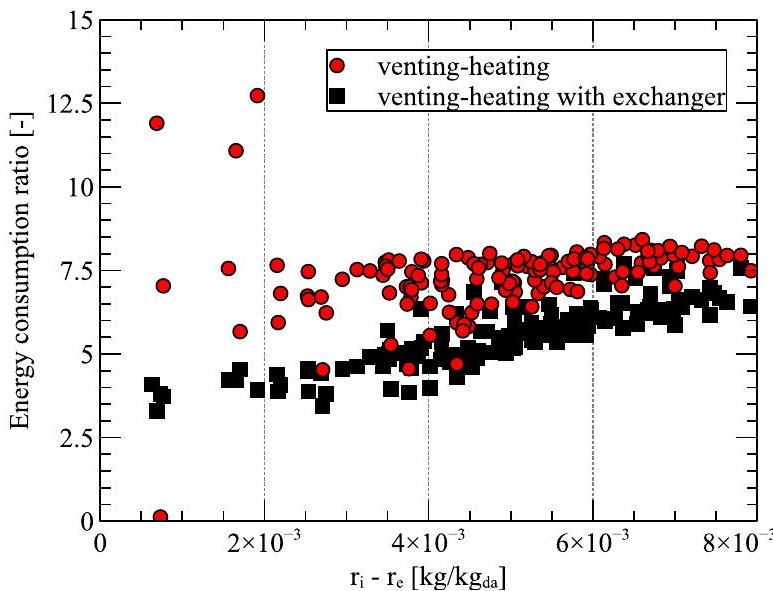




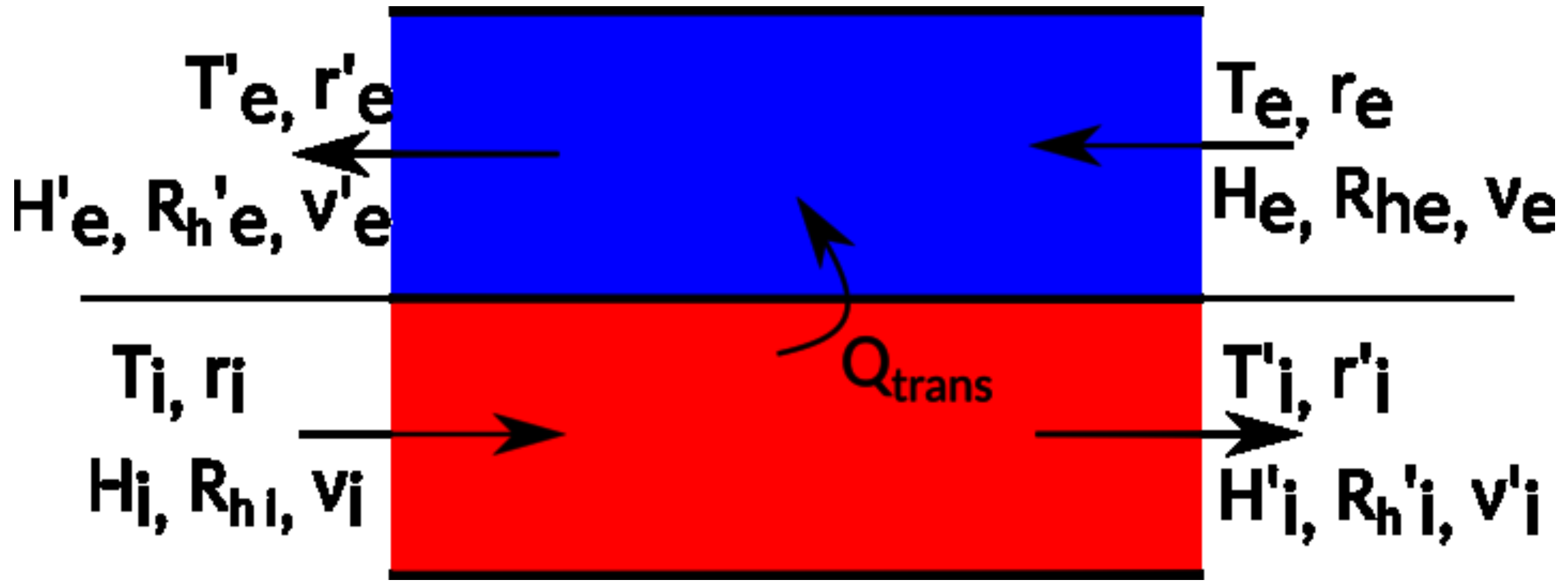




\begin{tabular}{|l|c|c|c|c|}
\hline \multicolumn{1}{|c|}{ Country } & $\begin{array}{c}\text { Natural gas prices } \\
\text { US\$/MWh }\end{array}$ & $\begin{array}{c}\text { Electricity prices } \\
\text { US\$/MWh }\end{array}$ & $\begin{array}{c}\text { Price ratio } \\
\text { gas/electricity }\end{array}$ & $\begin{array}{c}\text { Minimum power } \\
\text { consumption ratio } \\
\text { for cost equivalence }\end{array}$ \\
\hline Canada (2010 prices) & 13.8 & 69.9 & 0.20 & 5.1 \\
\hline France & 51.5 & 121.5 & 0.42 & 2.4 \\
\hline Germany & 54.4 & 157.2 & 0.35 & 2.5 \\
\hline Japan & 70.3 & 179 & 0.39 & 1.4 \\
\hline South Korea (2009 prices) & 41.2 & 57.8 & 0.71 & 3.4 \\
\hline Mexico (2008 prices) & 37.2 & 126 & 0.29 & 3.1 \\
\hline Netherland & 38.5 & 118.5 & 0.32 & 3.9 \\
\hline Spain & 37.7 & 148.8 & 0.25 & 3.6 \\
\hline United Kingdom & & & & \\
\hline
\end{tabular}

